\title{
ERROR DETERMINATION IN THE PHOTOGRAMMETRIC ASSESSMENT OF SHORELINE CHANGES
}

Del Río, Laura*(1) \& Gracia, F. Javier ${ }^{(1)}$

${ }^{(1)}$ Earth Sciences Department, CASEM, University of Cádiz. Av. República Saharaui s/n 11510 Puerto Real, Cádiz, Spain.

Tel. +34956016276. Fax +34956016195. E-mail: laura.delrio@uca.es

* Corresponding author

\begin{abstract}
The evaluation of error or uncertainty in shoreline change studies is an issue of prime importance for providing an adequate framework for calculated rates of change, and to allow the establishment of threshold values above which the rates would be significant. In this note a practical, easy-to-use method is presented to estimate error involved in the calculation of shoreline changes on aerial photographs, including the three most used types of shoreline indicators: high water line, dune/cliff toe and cliff top. This approach takes into account the specific characteristics of each shoreline proxy, such as relief in the case of the cliff top or tidal oscillations in the case of the high water line. At the same time it includes the error components that are independent from the proxy, basically related to the technical aspects of the process such as photo scanning and georeferencing. A practical example of application of the method is provided for several types of data inputs, based on shoreline changes around the Bay of Cadiz (SW Spain).
\end{abstract}

\section{Keywords}

Photogrammetry, coastal erosion, shoreline changes, aerial photography, error 


\section{Introduction}

Shoreline erosion constitutes one of the most serious natural hazards in many coastal areas worldwide. It can be considered an essentially natural process, but the increasing occupation of the coast has led to an increased risk, due to the growing exposure and the strong human influence on the stability of coastal systems.

As a consequence of this, the assessment of shoreline change trends is an issue of prime importance for coastal scientists and managers worldwide. In this regard, several authors have highlighted the need for adequate methods that can be used to estimate the amount of error or uncertainty in calculated rates of shoreline change (Anders and Byrnes 1991; Crowell et al. 1993; Moore 2000). These estimations provide an adequate framework for calculated rates of change and allow the establishment of threshold values above which the rates would be significant.

The analysis of vertical aerial photographs is the most commonly used technique in coastal erosion studies, especially for quantifying medium-term shoreline recession rates (Moore 2000), due to the generally wide availability and low cost of the materials. The use of photogrammetry in the assessment of shoreline change involves diverse sources of error or uncertainty that must be taken into consideration: errors in the original data, interpretation errors, measurement errors, etc. (Coyne et al. 1999; Moore 2000; Morton et al. 2004). In this note a specific method is proposed for the quantification of the various sources of error affecting the most common procedures and shoreline proxies used when employing aerial photographs for coastal change assessments.

\section{Sources of error in the photogrammetric process}

When using vertical aerial photographs for measuring shoreline changes, the first and most evident source of uncertainty is constituted by the intrinsic distortions affecting the photographs. These distortions are due to different causes related to the geometry of the aerial photographs (Gorman et al. 1998; Wolf and Dewitt 2000):

- Changing altitude of the aircraft along the line of flight due to atmospheric turbulences, causing scale changes between adjacent photographs.

- Camera tilt of the aircraft, producing not truly vertical but slightly oblique aerial photographs and hence distorting the scale of the photographs.

- Terrain relief, that due to the central perspective of the photographs causes an outward/inward displacement (called topographic displacement or relief displacement) of the elements located above/below mean ground level, such as cliffs or buildings. 
- Lens distortion, producing a radial deformation of the photograph.

The two main consequences of these phenomena are scale changes between and within photographs, and shifting of objects in the photographs away from true geographic location (Wolf and Dewitt 2000). As a consequence of this, aerial photographs should not be treated as maps (Anders and Byrnes 1991) and they must be corrected before using them for the quantification of shoreline changes (Gorman et al. 1998; Moore 2000; Boak and Turner 2005).

Coastal scientists often have digital orthophotographs available for recent periods (typically from 1990's onward) and paper photographs for earlier periods. Orthophotographs are truly vertical aerial photographs whose perspective has been changed from central to orthographic by using a highresolution DEM of the study area, specific information on the camera used (camera calibration and orientation parameters) and specialized software (Hapke and Richmond 2000), resulting in complete removal of the aforementioned distortions. On the other hand, the minimization of distortions in historical aerial photographs is achieved by scanning and georeferencing processes. This procedure provides a common geographic reference system that enables digital photograph overlapping and thus coastal change measurements, and the process results in a geometric correction of most of the aforementioned distortions (Hughes et al. 2006), except the highest relief displacements, that can only be removed by orthorectification (Moore and Griggs 2002). Therefore, geometric correction is generally considered adequate for coastal areas without high cliffs (Hughes et al. 2006).

Georeferencing of historical photographs is usually accomplished in GIS environment by using polynomic corrections based on ground control points (GCPs) identified on the photograph. The realworld coordinates of the GCPs are derived either from DGPS field surveys or from other mapping sources such as digital maps or orthophotographs from the same area. GCPs must be carefully chosen according to the general criteria of appropriate number, location and distribution established by authors like Moore (2000) or Wolf and Dewitt (2000). This way, on each photograph an adequate number of GCPs should be identified, evenly distributed across the whole photograph and mostly located on human landscape features such as crossroads. If the photographs are intended to be used for calculating shoreline rates of change as accurate as possible, Root Mean Square Error (RMSE) for the GCPs should generally be less than one-half the pixel size of the image (Vanderstraete et al. 2003) according to the US National Map Accuracy Standards (Stathopoulou and Cartalis 2009). After this process is completed, geometrically corrected photographs and orthophotographs from the same areas are superimposed on GIS environment in order to assess temporal changes in shoreline position.

At this stage, once the georeferenced photographs and/or orthophotographs are ready for shoreline mapping, a key issue is the selection of an adequate feature that can serve as a shoreline proxy or indicator, so that it properly reflects real shoreline position and evolution (Pajak and Leatherman 
2002; Boak and Turner 2005). This choice constitutes a complex problem, as the shoreline proxy should also be clearly identifiable on aerial photographs and should not be influenced by short-term processes that can mask real medium-term trend (Moore 2000). In this regard, the dynamic nature of land-sea limit has led to a variety of criteria, so a wide range of geomorphological features have been used as shoreline indicators by different authors (Boak and Turner 2005). The proxies are generally chosen according to local geomorphological characteristics of the coastal sectors to be studied, and they include beach toe, wet/dry line, erosion scarp, stable vegetation line, dune toe, dune crest, cliff toe, cliff top, etc. (Coyne et al. 1999; Pajak and Leatherman 2002; Fletcher et al. 2003; Boak and Turner 2005, among others). However, the most common proxies are the wet/dry line (Crowell et al. 1991), the vegetation line (Garcia et al. 2010), the dune toe (Schwarzer et al. 2003) and the cliff top (Moore and Griggs 2002).

The wet/dry line identifiable on the photographs, that is usually the last high tide mark, constitutes the most widely used shoreline proxy (Pajak and Leatherman 2002; Boak and Turner 2005) and is commonly considered equivalent to or closely approximating the high water line (HWL) (Crowell et al. 1997). Despite its limitations regarding short-term variability, that will be discussed later, it is generally deemed as a valid indicator of shoreline position (Gorman et al. 1998). In fact, in some cases the wet/dry line is the only indicator available, as occurs in highly developed coasts where the beach is backed by a seawall, riprap revetment or other artificial structure. At coastal traits where dunes are present, the dune toe (considered as the contact between backshore and foredune) is usually chosen as shoreline proxy, with the aim of using an indicator that is independent of meteorological conditions, waves, tides and beach profile shape (Moore and Griggs 2002; Schwarzer et al. 2003). Likewise, the cliff top is normally employed as shoreline proxy at cliffed coastal sectors (Catalão et al. 2002). However, in those areas where gentle cliff slope, presence of vegetation, rounded cliff edge or extensive development prevent a proper identification of the cliff top line, the cliff toe is used as shoreline indicator (Pierre 2006). It must be pointed out that each proxy has its own advantages and disadvantages, which must be kept in mind and balanced when using these indicators.

Once the proper shoreline proxies are identified on each photograph, the next step is the actual shoreline mapping, which is generally performed by on-screen digitizing in GIS environment. Sometimes manual or computer-based stereoscopes are used to assist in the process, especially when relief is essential in the identification of the shoreline indicator, as in the case of cliff top. Additional interpretation errors and inaccuracies may arise in the digitizing process, mainly related to: i) poor photo contrast hindering the interpretation of shoreline position, and ii) presence of several shoreparallel lines (flotsam line, erosional scarp, etc.) that may be confused with the chosen shoreline proxy (Moore 2000). 
Finally, after all shorelines are digitized, various techniques can be used to evaluate shoreline recession/advance distances and to compute rates of shoreline change (Morton et al. 2004; Genz et al. 2007). The most common approach involves drawing of shore-normal transepts at a certain distance apart, and computation of change rates between the different shorelines along each transept, either manually or automatically (Thieler et al., 2005). The influence of sampling and computation factors such as the number of shorelines available, the time interval between shorelines, the time span of the shoreline record or the calculation method in the overall uncertainty of resulting shoreline trends has been studied by several authors (e.g. Dolan et al. 1991; Crowell et al. 1993; Fenster et al. 2001; Honeycutt et al. 2001) and is out of the scope of this work.

\section{Estimating uncertainty in shoreline change calculations}

To sum up, factors causing uncertainty in shoreline change studies can be grouped into three classes:

- Factors that produce a displacement of the shoreline from its true position on the photograph, essentially due to the way aerial photos are taken. These are mainly lens distortion, terrain relief, changes in aircraft altitude and camera tilt (Anders and Byrnes 1991; Thieler and Danforth 1994).

- Factors that hinder proper interpretation and identification of the shoreline position on a photograph, generally related to image scale and processing techniques. This group mostly includes the loss of image resolution or contrast due to paper photo scanning and the errors deriving from photo georeferencing (Fletcher et al. 2003).

- Factors that cause the non-representativeness of the shoreline identified in the photograph, mainly associated to short-term variations in shoreline proxy and/or shoreline changes not related to real coastal erosion or accretion processes (Dolan et al. 1991; Moore 2000). These factors can lead to sampling errors in shoreline position (Coyne et al. 1999; Morton et al. 2004), both in the temporal (e.g. photographs taken after storm events or beach nourishments) and spatial aspects (e.g. use of stabilized cliffs or restored dunes as shoreline indicators) (Fig. $1)$.

Most of the errors generated by the aforementioned factors can be avoided to a certain extent by common procedures such as focusing on the central part of each photo, scanning the paper photos at a very high resolution, performing geometric corrections on GIS software, using only summer aerial photographs, etc. However, there is always some degree of uncertainty in the interpreted shoreline positions and in the derived rates of shoreline change, so it is necessary to quantify or at least estimate, as far as possible, that uncertainty. This need is acknowledged by several authors (Anders and Byrnes 
1991; Crowell et al. 1993; Moore 2000), but there are few specific proposals for error assessment in shoreline mapping in the literature. In this regard, methods are often based on measuring distances on the photograph, taking fixed elements as a reference, and comparing the measurements in diverse photographs or with a reference document (Catalão et al. 2002; Ferreira et al. 2006). In other cases the methods proposed are aimed at quantifying some of the factors causing error, such as image resolution or short-term shoreline variability (Coyne et al. 1999; Fletcher et al. 2003; Zviely and Klein 2004). Nearly all these methods use solely the HWL as shoreline proxy (Shoshany et al. 1996; Morton et al. 2004), and they are often quite imprecise and difficult to apply directly.

For these reasons, in this note a practical, easy-to-use technique is presented to estimate error involved in the calculation of shoreline changes on aerial photographs, including the three most used types of shoreline indicators, i.e. HWL, dune/cliff toe and cliff top. This approach takes into account the specific characteristics of each shoreline proxy, such as relief in the case of the cliff top or tidal oscillations in the case of the HWL. At the same time it includes the error components that are independent from the proxy, basically related to the technical aspects of the process (scanning and georeferencing).

The method is based on the assumption that the cumulative uncertainty in shoreline position digitized on an aerial photograph is the result of three simultaneous factors that are consecutively added on each stage of the process:

1) Scanning error, represented by the image resolution (R) (Coyne et al. 1999; Catalão et al. 2002).

2) Georeferencing error $(\mathrm{G})$, represented by the RMSE of the georeferencing process (Shoshany et al. 1996; Morton et al. 2004).

3) A physical component of the error (D), related to the specific characteristics of each shoreline proxy.

The first component of uncertainty corresponds to the scanning or digital capture processes of the original photographs or orthophotographs. It is represented by image pixel size (Coyne et al. 1999; Catalão et al. 2002), since the larger the pixels, the larger the uncertainty in interpreting shoreline position on the photograph. From the Shannon sampling theorem it arises that when selecting scanning resolution, pixel size should be set to at least one-half of the minimum spacing (smallest feature) that needs to be resolved on the photograph (Weeks 1996, Lehmbeck and Urbach 2004). However, it must be noted that the improvement of image resolution by changing the scanning mode is not infinite, so oversampling should be avoided.

The second component of error relates to the geometric correction of the photographs, expressed by the RMS error of the process (Shoshany et al. 1996; Morton et al. 2004). It must be noted that the 
quality of the fit of the transformation equations to the GCPs expressed by the RMSE is not completely equivalent to the positional accuracy of the georectified image (Hughes et al. 2006). However, as a statistical measure it constitutes a widely accepted estimation of the general accuracy of the process, and as such is used in this approach.

As for the third component of error, it is defined according to the shoreline indicator used. In case of using the HWL as shoreline proxy, D factor represents the short-term variability in shoreline position resulting from tide oscillation, the so-called "tidal stage uncertainty" (Fletcher et al. 2003). This includes the changing high water level due to alternating spring-neap tides, as well as the horizontal variability of high water mark resulting from changes in beach slope. It is clear that the position of the HWL is also influenced by waves and storm surges, but most photogrammetric flights are generally performed under fair weather conditions in spring or summer periods, so this aspect is not included in the present proposal. Nevertheless, in case that post-storm photography cannot be avoided, then the local variability of the HWL during storms should be estimated and included in error calculations (Moore, 2000).

This way, when using the HWL as shoreline indicator, D factor is geometrically calculated as the horizontal variability in shoreline position resulting from a certain tide height $(\mathrm{M})$ on a beach profile with a certain slope $(\tan \beta)($ Allan et al. 2003) (Eq. 1):

$D_{H W L}=M / \tan \beta$

In this expression $\mathrm{M}$ is computed in a different way according to the information available on tide conditions on each photograph. If the exact date and time of the photograph (and hence tide situation) is unknown, $\mathrm{M}$ is computed as (plus/minus) half the maximum difference between spring and neap high tide levels in the study area, in order to obtain maximum horizontal displacement of the HWL in a worst-case approach. Conversely, if the exact date and time are known and so is high water level, the value of $\mathrm{M}$ is directly calculated as the height difference between the two high waters in the two photographs that are being compared. This way, in the first case the D factor of error is computed for each shoreline position, while in the second case the $\mathrm{D}$ factor is a single value that represents the uncertainty in the variation between two shoreline positions due to the different high water levels in two photographs.

In case of using the cliff top as shoreline indicator, the D component of error represents relief displacement, which is partly but not completely removed by geometric correction. The magnitude of relief displacement depends on cliff height, cliff position in the aerial photograph, image scale and characteristics of the georeferencing process (Anders and Byrnes 1991; Zviely and Klein 2004). The further the cliff is from the center of the image and the higher its height, the larger the displacement of 
cliff top from its true position. The displacement also increases in low altitude (i.e. large scale) aerial photographs. On the other hand, the greater the number of GCPs used in the geometric correction, the higher the chances of reducing relief displacement and hence the lower the uncertainty in cliff top position. Therefore, the $\mathrm{D}$ component of error is computed as (Eq. 2):

$D_{T O P}=(S \times d \times h / H) / \sqrt{n}$

where $\mathrm{S}$ is image scale, $\mathrm{d}$ is the distance from the cliff top to the principal point of the photograph, $\mathrm{h}$ is cliff height, $\mathrm{H}$ is flight height and $\mathrm{n}$ is the number of GCPs used in the georeferencing process. If digital orthophotographs are used, the $\mathrm{D}$ factor is zero, as orthorectification removes relief displacement.

Finally, where dune foot or cliff toe are employed as shoreline proxies, the D factor is also considered as zero, due to the relative independence of these indicators from both short-term variability and relief displacement errors.

Once the three components of error (scanning, georeferencing and physical component) are calculated, the total uncertainty in shoreline position on a certain photograph $\left(E_{\mathrm{P}}\right)$ is computed as the quadratic sum of each component (Coyne et al. 1999; Fletcher et al. 2003) according to Equation 3:

$$
E_{P}=\sqrt{G^{2}+R^{2}+D^{2}}
$$

The errors calculated by means of Equation 3 correspond to each individual image, so when comparing two shoreline positions extracted from two separate photographs (P1 and P2) the error is cumulative (Anders and Byrnes 1991). Consequently, the total uncertainty for a given rate of shoreline change calculated between two shoreline positions should be computed by considering both individual errors, as well as the time span between the two photographs in order to annualize the total error (Fletcher et al. 2003; Morton et al. 2004) (Eq. 4):

$$
E_{\text {RATE }}=\sqrt{E_{P 1}^{2}+E_{P 2}^{2}} / T
$$

where $\mathrm{T}$ is the time span (in years) between the two photographs from where the shorelines were extracted. The overall process is summarized in Figure 2. 


\section{Example of application to the Bay of Cadiz (Spain)}

In this section a practical example is provided on the application of the proposed method to the determination of errors in shoreline change rates calculated in the Bay of Cadiz (SW Spain). Three different cases are considered with diverse type of data inputs.

\subsection{Cliff top as shoreline proxy}

The study site is El Almirante embayment, located in the northern Bay of Cadiz, in the N.A.T.O. Naval Station at Rota (Fig. 3). Here significant coastal erosion has been recorded over the last 50 years, mainly caused by sediment starving affecting the beach downdrift of the large harbour of the Naval Station, together with rock falls and slides affecting the soft cliff backing the beach (Cooper et al. 2009; Del Río and Gracia 2009).

In this particular example the cliff top is used as a shoreline proxy to determine cliff recession rates between 1994 and 2002, by using a 1994 scanned aerial photograph and a 2002 orthophotograph. In order to compute the uncertainty involved in the calculation of shoreline change rates, the characteristics of each photo are shown in Table 1.

By applying eq. 3 to G, R and D parameters a total error of $1.68 \mathrm{~m}$ is obtained for the cliff top position derived from the 1994 photo, this value being $0.5 \mathrm{~m}$ in the 2002 orthophotograph. The time interval between the dates when the photos were taken (07/15/1994 and 08/07/2002) is 8.07 years, which according to eq. 4 gives a total error in the rates of shoreline change between both dates of $\pm 0.22 \mathrm{~m} / \mathrm{yr}$.

This result would mean that cliff recession rates would only be significant if they are above this threshold. In the case of El Almirante, cliff top retreat between 1994 and 2002 has been evaluated to range between $0.2 \mathrm{~m} / \mathrm{yr}$ at its western sector (a non-significant erosion rate) and $1.8 \mathrm{~m} / \mathrm{yr}$ at its eastern sector, with several erosion hotspots having retreated up to $2.5 \mathrm{~m} / \mathrm{yr}$ in the aforementioned period (Del Río, 2007).

\subsection{High water line as shoreline proxy (dates known)}

The study site is Camposoto-El Castillo beach, located in Sancti-Petri sandspit at the southern end of the Bay of Cádiz (Fig. 3). Shoreline changes in this area are spatially irregular and related to a combination of factors, including general reduction in sediment supply to the coast caused by river damming, discontinuities in the offshore rocky shoal fronting the beach, and dune weakening by human transit (Del Río, 2007). 
In this area both the dune toe and the HWL could be used as indicators of shoreline position. Since error calculation in dune toe proxies is straightforward (Fig. 2), here an example of the HWL is presented, in which the dates of the photographs analysed are known. In this example shoreline change is assessed over the period between 1986 and 2002, by using a 1986 scanned aerial photograph and a 2002 orthophotograph. The characteristics of each photo are shown in Table 2.

In this case the application of eq. 3 to each photo only considers $\mathrm{G}$ and $\mathrm{R}$ factors, as the $\mathrm{D}$ factor is not computed separately for each shoreline position, but represents a single value of the error derived from the tidal variation of the HWL between both photos. This results in a total uncertainty of $1.10 \mathrm{~m}$ for the 1986 photo and $0.5 \mathrm{~m}$ for the 2002 orthophotograph, which are then combined and annualized as in the previous example (eq. 4) according to the 16.31 years interval between the photos (taken on the $04 / 30 / 1986$ and the 08/16/2002). The total value of $\mathrm{D}$ factor is added afterwards, yielding a total uncertainty for the rate of shoreline change between both dates of $\pm 0.27 \mathrm{~m} / \mathrm{yr}$.

As in the cliff top example, the computed shoreline change rates (accretion or erosion) must be compared with the obtained value of error in order to check their significance. In Camposoto-El Castillo beach an irregular but definitely erosive trend of the HWL has been detected, with recession rates between 0.6 and $1.7 \mathrm{~m} / \mathrm{yr}$ in the period 1986-2002 (Del Río, 2007), clearly higher than the range of error and thus fully significant.

\subsection{High water line as shoreline proxy (dates unknown)}

The study case is La Victoria urban beach, located in Cádiz city, in the outer Bay of Cádiz (Fig. 3). Here shoreline changes are highly influenced by human interventions, namely artificial nourishments that have been carried out several times over the last two decades in order to maintain a wide dry beach for tourism (Del Río, 2007).

The beach is backed by a promenade and there are no dunes or other natural features that can be used as shoreline indicators, so the only proxy available is the HWL. In this example two photographs have been used for which the exact date is not known, so it is not possible to calculate the real difference between the two high waters as in the previous example. Specifically, the images used were two scanned aerial photographs from 1977 and 1994, whose characteristics are shown in Table 3.

The fact that the exact dates of the photographs are not known means that the $\mathrm{D}$ factor is computed in a worst-case approach as the maximum variability of the HWL due to the alternating spring and neap tidal cycles. By applying eq. 3 total error values of $9.42 \mathrm{~m}$ and $9.40 \mathrm{~m}$ are obtained for the HWL position in the 1977 and 1994 photos, respectively. For calculating the time interval between both photographs an estimation is employed, by considering the central date of the known month or year 
when each photo was taken (in this case 06/30/1977 and 07/15/1994). The resulting time interval of 17.05 years is used for annualizing the uncertainty, thus yielding a total error in the rate of shoreline change of $\pm 0.78 \mathrm{~m} / \mathrm{yr}$.

In this case the comparison of the obtained uncertainty with calculated changes in the HWL results in the latter not being significant in the southern sector of La Victoria beach, where rates of shoreline change in the period 1977-1994 are between $-0.4 \mathrm{~m} / \mathrm{yr}$ and $0.6 \mathrm{~m} / \mathrm{yr}$, i.e. lower that the error range (Del Río, 2007). However in the northern and central sectors the HWL shows a very significant advance of between 1.1 and $4.5 \mathrm{~m} / \mathrm{yr}$ in the same period (Del Río, 2007), directly related to the massive artificial nourishment works performed in 1991 along the beach (Muñoz-Pérez et al., 2001). In this regard, the fact that the southern sector is not showing the effect of the nourishment reflects a trend towards net sand loss in this area.

\section{Final considerations}

In this note a simple method is proposed for evaluating the uncertainty range involved in the calculation of shoreline change rates from aerial photographs. For this purpose the different sources of error that affect the photogrammetric process are considered, as well as the specific sources of error related to coastal features used as shoreline proxies. This procedure provides an adequate context to shoreline change mapping and measurement, thus contributing to determine whether the obtained rates of coastal change are significant or not.

The method relies on data that are generally available or easy to obtain, such as image resolution, RMSE of the georeferencing process, height of the photogrammetric flight, tide characteristics in the study area, and others. When the HWL is used as shoreline indicator the average intertidal beach slope is one of the parameters needed for determining uncertainty. In this case some error may arise from the fact that in most coastal areas there are typically no data available on beach slope for periods prior to the 1980s, so recent or present-day data must be extrapolated to photographs dating from several decades ago. Moreover, beach slope changes seasonally, so the use of average figures may induce additional errors; if there are different data available, the best option is to use the slope that is closest to the month of year when the photo was taken.

It must be mentioned that the examples provided in this paper involve only two consecutive shorelines, while coastal scientists commonly have photographs available from several dates. In that case a value of error should be computed for each pair of shorelines, and the average of those errors would be adopted as the mean uncertainty of the total rate of shoreline change. 
It is also important to note that, apart from the previously mentioned parameters, the general accuracy of shoreline change rates obtained from aerial photographs can also be influenced by other factors, which are however not objective or feasible to quantify, so they are not considered in this note. For example, when choosing the dune toe or the cliff top as shoreline proxies, it is clear that the use of stereoscopic pairs that allow 3D viewing will result in more accurate shoreline mapping and less error in derived rates of change. Conversely, overexposed photographs usually hinder the accurate identification of proxies such as the dune toe and the HWL, as their position is often masked by extremely bright beach sand.

On a further step other factors related to shoreline sampling and rate-of-change calculation methods could be included in the assessment of total uncertainty. However, this would involve developing specific techniques for computing errors associated to the number of shorelines used, the possible presence of outliers in the shoreline record, the time interval between shorelines, the total time span of the shoreline record, the method used for calculating rates of change, and so on. The resultant method would probably be very complex and require many variables and factors to be separately computed, so it would not be as practical and easy to use as the one proposed in this work.

\section{Acknowledgements}

This work is a contribution to the research group RNM-328 of the Andalusian Research Plan (PAI).

\section{References}

Allan JC, Komar PD, Priest GR (2003) Shoreline variability on the high-energy Oregon coast and its usefulness in erosion-hazard assessments. J Coastal Res SI 38:83-105

Anders FJ, Byrnes MR (1991) Accuracy of shoreline change rates as determined from maps and aerial photographs. Shore \& Beach 59 (1):17-25

Boak EH, Turner IL (2005) Shoreline definition and detection: a review. J Coastal Res 21(4):688-703

Catalão J, Catita C, Miranda J, Dias JA (2002) Photogrammetric analysis of coastal erosion in the Algarve (Portugal). Geomorphologie 2:119-126

Cooper JAG, Anfuso G, Del Río L (2009) Bad beach management: European perspectives. Geol S Am S 460:167-179 
Coyne MA, Fletcher CH, Richmond BM (1999) Mapping coastal erosion hazards in Hawaii: observations and errors. J Coastal Res SI 28:171-184

Crowell M, Douglas BC, Leatherman S (1997) On forecasting future US shoreline positions: a test of algorithms. J Coastal Res 13 (4):1245-1255

Crowell M, Leatherman SP, Buckley MK (1991) Historical shoreline change: Error analysis and mapping accuracy. J Coastal Res 7 (3):839-852

Crowell M, Leatherman S.P., Buckley MK (1993) Shoreline change rate analysis: Long term versus short term data. Shore \& Beach 61 (2):13-20

Del Río L (2007). Riesgos de erosión costera en el litoral atlántico gaditano. PhD Dissertation, Universidad de Cádiz

Del Río L, Gracia FJ (2009) Erosion risk assessment of active coastal cliffs in temperate environments. Geomorphology 112:82-95

Dolan R, Fenster MS, Holme SJ (1991) Temporal analysis of shoreline recession and accretion. J Coastal Res 7 (3):723-744

Fenster MS, Dolan R, Morton RA (2001) Coastal storms and shoreline change: signal or noise? J Coastal Res 17 (3):714-720

Ferreira O, García T, Matias A, Taborda R, Alveirinho Dias J (2006) An integrated method for the determination of set-back lines for coastal erosion hazards on sandy shores. Cont Shelf Res 26:10301044

Fletcher C, Rooney J, Barbee M, Lim S, Richmond BM (2003) Mapping shoreline change using digital ortophotogrammetry on Maui, Hawaii. J Coastal Res SI 38:106-124

Garcia T, Ferreira O, Matias A, Alveirinho Dias J (2010) Overwash vulnerability assessment based on long-term washover evolution. Nat Hazards 54(2):225-244

Genz AS, Fletcher CH, Dunn RA, Frazer LN, Rooney J (2007) The predictive accuracy of shoreline change rate methods and alongshore beach variation on Maui, Hawaii. J Coastal Res 23 (1): 87-105

Gorman L, Morang A, Larson R (1998) Monitoring the coastal environment. Part IV: Mapping, shoreline changes, and bathymetric analysis. J Coastal Res 14 (1): 61-92 
Hapke CJ, Richmond BM (2000) Monitoring beach morphology changes using small-format aerial photography and digital softcopy photogrammetry. Environ Geosci 7 (1):32-37

Honeycutt MG, Crowell M, Douglas BC (2001) Shoreline-position forecasting: Impact of storms, ratecalculation methodologies, and temporal scales. J Coastal Res 17 (3):721-730

Hughes ML, McDowell PF, Marcus WA (2006) Accuracy assessment of georectified aerial photographs: implications for measuring lateral channel movement in a GIS. Geomorphology 74:1-16

Lehmbeck DR, Urbach JC (2004) Image quality for scanning. In: Marshall GF (ed) Handbook of optical and laser scanning, Taylor and Francis, New York, pp 154-300

Moore LJ (2000) Shoreline mapping techniques. J Coastal Res 16(1):111-124

Moore LJ, Griggs GB (2002) Long-term cliff retreat and erosion hotspots along the central shores of the Monterey Bay National Marine Sanctuary. Mar Geol 181:265-283

Morton RA, Miller TA, Moore LJ (2004) National assessment of shoreline change: Part 1 - Historical shoreline changes and associated coastal land loss along the US Gulf of Mexico. USGS OFR 20041043

Muñoz JJ, López de San Román B, Gutiérrez-Mas JM, Moreno L, Cuena GJ (2001) Cost of beach maintenance in the Gulf of Cadiz (SW Spain). Coast Eng 42:143-153

Pajak MJ, Leatherman SP (2002) The high water line as shoreline indicator. J Coastal Res 18 (2):329337

Pierre G (2006) Processes and rate of retreat of the clay and sandstone sea cliffs of the northern Boulonnais (France). Geomorphology 73 (1-2):64-77

Schwarzer K, Diesing M, Larson M, Niedermeyer R, Schumacher W, Furmanczyk K (2003) Coastline evolution at different time scales - examples from the Pomeranian Bight, southern Baltic Sea. Mar Geol 194:79-101

Shoshany M, Golik A, Degani A, Lavee H, Gvirtzman G (1996) New evidence for sand transport direction along the coastline of Israel. J Coastal Res 12 (1):311-325

Stathopoulou M, Cartalis C (2009) Downscaling AVHRR land surface temperatures for improved surface urban heat island intensity estimation. Remote Sens Environ 113 (12):2592-2605 
Thieler ER, Danforth WW (1994) Historical shoreline mapping (I): Improving techniques and reducing positioning errors. J Coastal Res 10 (3):549-563

Thieler ER, Himmelstoss EA, Zichichi JL, Miller TL (2005) Digital Shoreline Analysis System (DSAS) version 3.0: An ArcGIS extension for calculating shoreline change. USGS Open-File Report 2005-1304

Vanderstraete T, Goosens R, Ghabour TK (2003) Remote sensing as a tool for bathymetric mapping of coral reefs in the Red Sea (Hurghada - Egypt). BELGEO 2003 (3):257-267

Weeks AR (1996) Fundamentals of electronic image processing. SPIE Optical Engineering Press, Bellingham, Washington

Wolf PR, Dewitt BA (2000) Elements of photogrammetry with applications in GIS. McGraw-Hill, Madison

Zviely D, Klein M (2004) Coastal cliff retreat rates at Beit-Yannay, Israel, in the 20th century. Earth Surf Proc Land 29:175-184 


\section{TABLE CAPTIONS}

Table 1. Parameters used in the determination of uncertainty for a cliff top proxy (G: RMSE of the georeferencing; R: pixel size; S: photo scale; d: distance to principal point; h: cliff top height; H: flight height; n: number of GCPs; D: physical component of error, obtained from eq. 2; N/A: not applicable).

Table 2. Parameters used in the determination of uncertainty for a HWL proxy with known dates (G: RMSE of the georeferencing; R: pixel size; $\mathrm{M}_{1-2}$ : height difference between the two high waters; $\tan \beta$ : intertidal beach slope; $\mathrm{D}_{1-2}$ : tide-related horizontal variability in HWL position between the two photographs; D: annualized physical component of error).

Table 3. Parameters used in the determination of uncertainty for a HWL proxy with unknown dates (G: RMSE of the georeferencing; R: pixel size; M: half the maximum difference between spring and neap high tide levels in the study area; $\tan \beta$ : intertidal beach slope; $D$ : maximum horizontal displacement of the HWL).

\section{FIGURE CAPTIONS}

Fig. $1 \mathrm{~A}$ and B: Example of uncertainty in determining HWL position due to short-term variability related to changing wave conditions (Valdevaqueros beach, Tarifa, Spain). C: Stabilized cliff where neither cliff top nor cliff toe should be used as shoreline proxies (Santa Catalina beach, El Puerto de Santa María, Spain) (Photo: Spanish Ministry of Environment). D: Restored dunes where dune toe advance would not be related to a real coastal accretion process (Camposoto beach, San Fernando, Spain)

Fig. 2 Flow diagram showing the procedure for error estimation

Fig. 3 Location of the study sites around the Bay of Cádiz (orthophotographs: Andalusian Cartographic Institute) 
Figure 1_Word format

Click here to download Figure: Fig1.doc
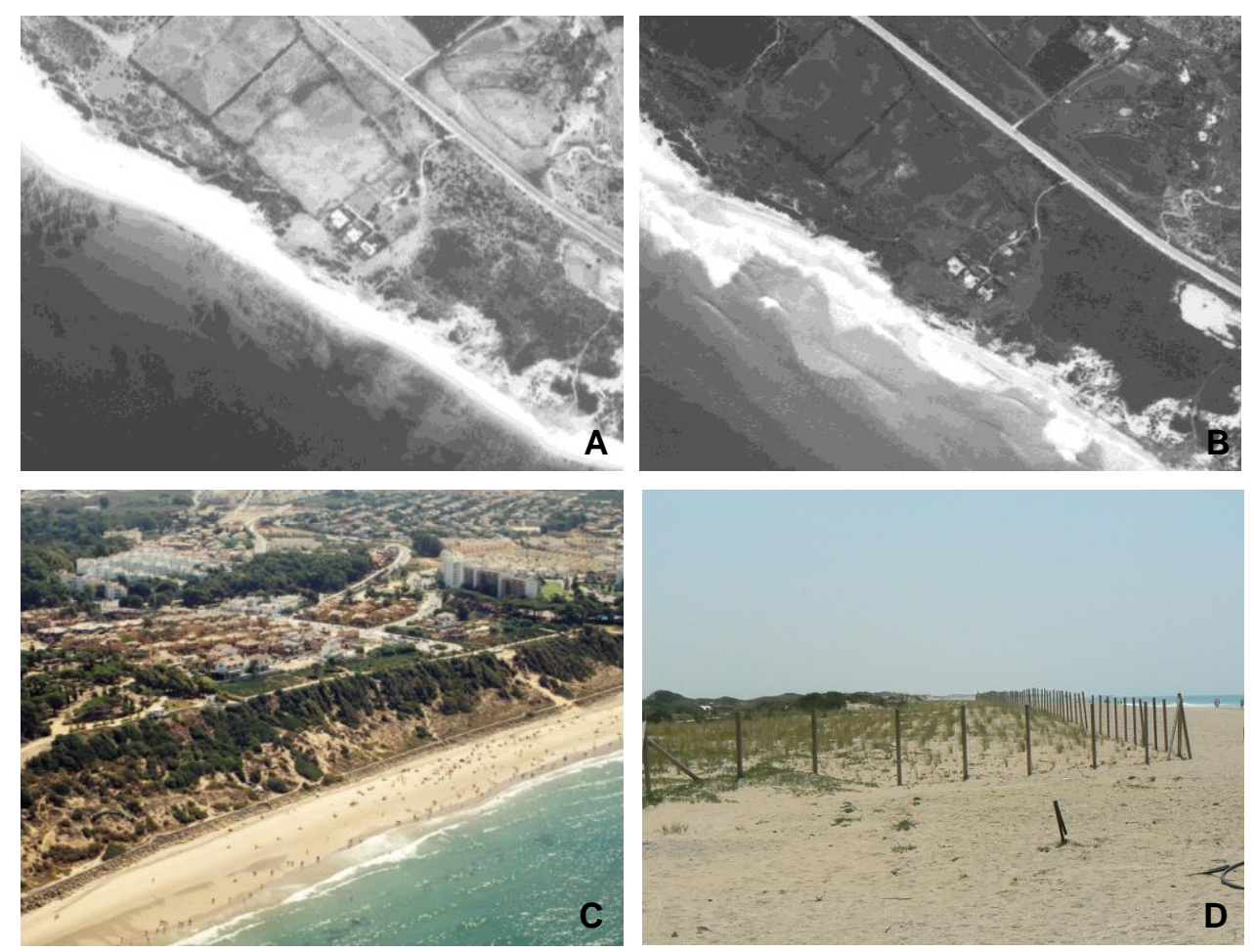


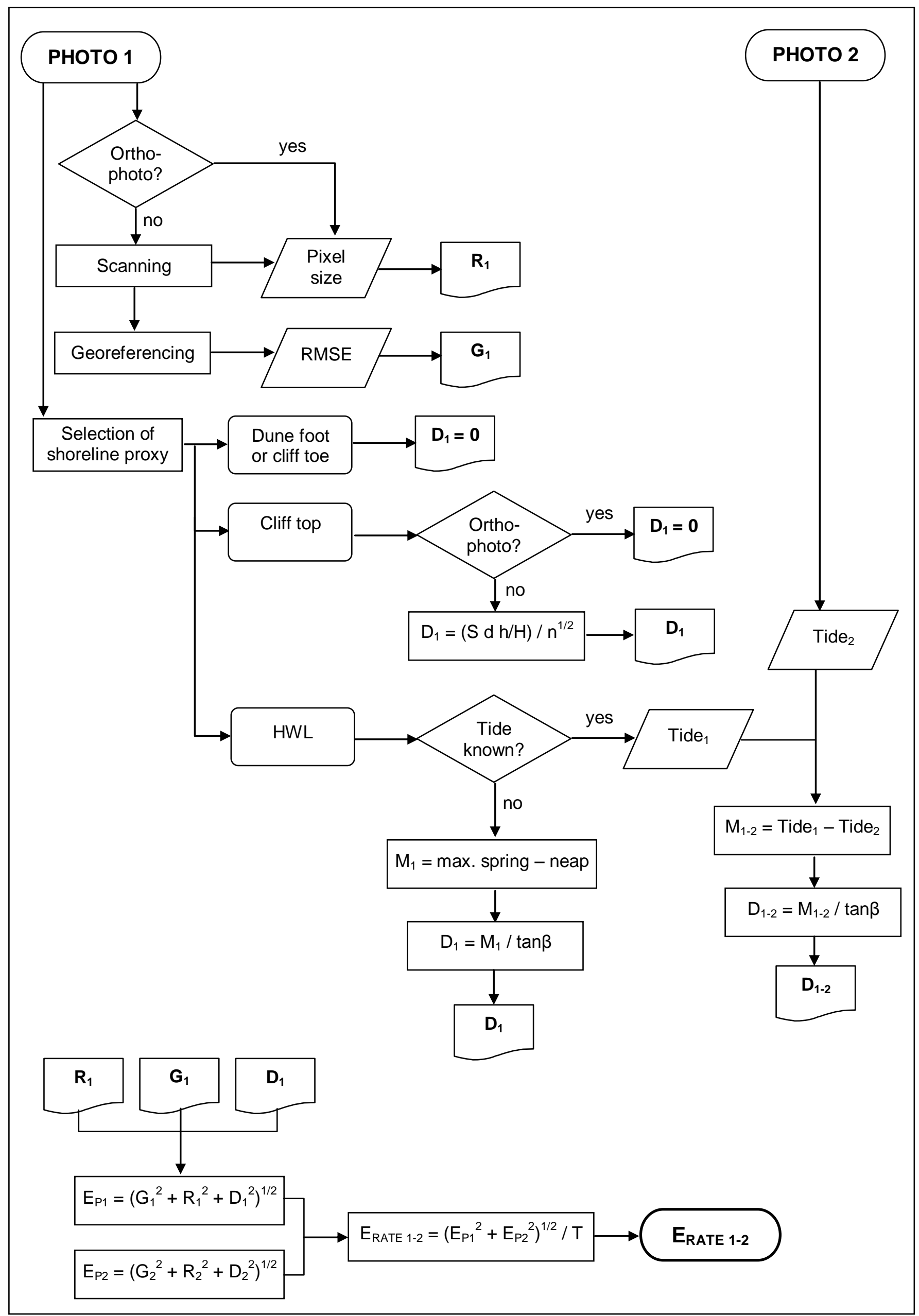




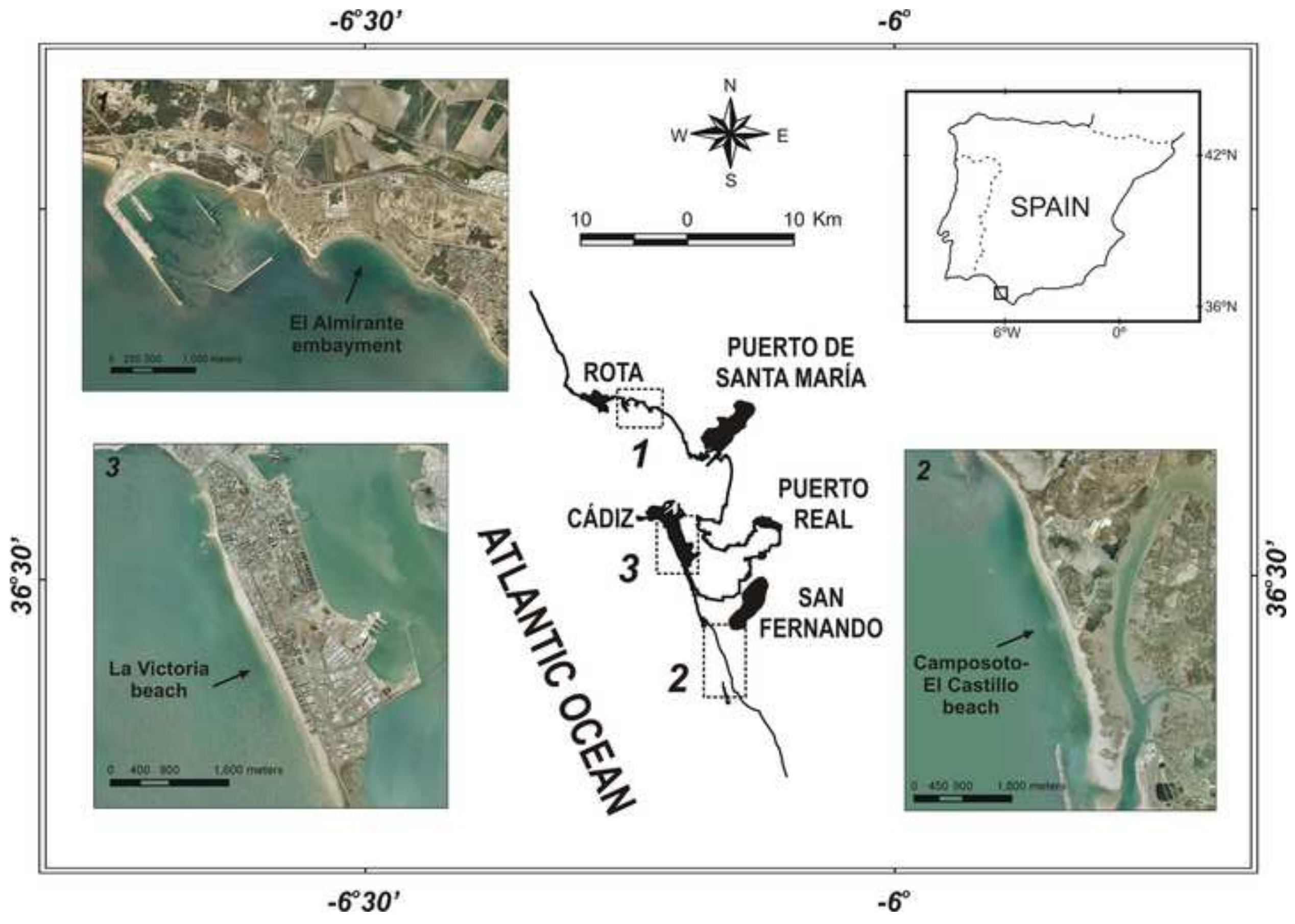


Click here to download table: Table1.doc

Table 1.

\begin{tabular}{ccccccccc}
\hline photo & $\mathbf{G}(\mathbf{m})$ & $\mathbf{R}(\mathbf{m})$ & $\mathbf{S}$ & $\mathbf{d}(\mathbf{m})$ & $\mathbf{h}(\mathbf{m})$ & $\mathbf{H}(\mathbf{m})$ & $\mathbf{n}$ & $\mathbf{D}(\mathbf{m})$ \\
\hline 1994 & 0.53 & 0.94 & $1: 15000$ & 0.09 & 13 & 2295 & 35 & 1.29 \\
\hline 2002 & 0 & 0.5 & N/A & N/A & N/A & N/A & N/A & 0 \\
\hline
\end{tabular}


Table 2

Click here to download table: Table2.doc

Table 2.

\begin{tabular}{cccccccc}
\hline photo & $\mathbf{G}(\mathbf{m})$ & $\mathbf{R}(\mathbf{m})$ & $\mathbf{M}_{\mathbf{1 - 2}}(\mathbf{m})$ & $\tan \boldsymbol{\beta}$ & $\mathbf{D}_{\mathbf{1 - 2}}(\mathbf{m})$ & interval $(\mathbf{y r})$ & $\mathbf{D}(\mathbf{m})$ \\
\cline { 1 - 3 } 1986 & 0.37 & 1.03 & 0.23 & 0.069 & 3.32 & 16.31 & 0.20 \\
\cline { 1 - 3 } 2002 & 0 & 0.5 & & & & & \\
\hline
\end{tabular}


Table 3

Click here to download table: Table3.doc

Table 3.

\begin{tabular}{|c|c|c|c|c|c|}
\hline photo & G (m) & $\mathbf{R}(\mathbf{m})$ & $\mathbf{M}(\mathbf{m})$ & $\tan \beta$ & $\mathbf{D}(\mathrm{m})$ \\
\hline 1977 & 0.50 & 1.02 & \multirow{2}{*}{ \pm 0.45} & \multirow{2}{*}{0.048} & \multirow{2}{*}{9.35} \\
\hline 1994 & 0.35 & 0.92 & & & \\
\hline
\end{tabular}

